Revista de la red interuniversitaria de estudios sobre las literaturas rioplatenses contemporáneas en Francia

16 | 2017

Esnobismos

\title{
Las amenazas de una dinastía espuria. Sirvientes que no sirven en Manuel Mujica Lainez
}

\section{María Julia Rossi}

\section{OpenEdition}

\section{Journals}

Electronic version

URL: http://journals.openedition.org/lirico/3666

DOI: $10.4000 /$ lirico.3666

ISSN: 2262-8339

\section{Publisher}

Réseau interuniversitaire d'étude des littératures contemporaines du Río de la Plata

\section{Electronic reference}

María Julia Rossi, «Las amenazas de una dinastía espuria. Sirvientes que no sirven en Manuel Mujica Lainez », Cuadernos LIRICO [En línea], 16 | 2017, Puesto en línea el 02 octubre 2017, consultado el 30 abril 2019. URL : http://journals.openedition.org/lirico/3666 ; DOI : 10.4000/lirico.3666

This text was automatically generated on 30 April 2019.

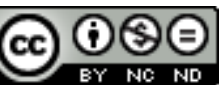

Cuadernos LIRICO está distribuido bajo una Licencia Creative Commons Atribución-NoComercialSinDerivar 4.0 Internacional. 


\title{
Las amenazas de una dinastía espuria. Sirvientes que no sirven en Manuel Mujica Lainez
}

\author{
María Julia Rossi
}

Mis queridos lacayos, tan absurdamente envanecidos en un momento y tan abyectos en el inmediato, no son sino el reflejo de sus amos en este mundo. Aquel que admira mezquinamente cosas mezquinas es un snob : acaso sea esta la definición exacta de este tipo. William M. Thackeray

El libro de los snobs, 100 (cursiva en el original)

\section{Mujica Lainez, el esnobismo}

Cuenta Manuel Mujica Lainez que en su adolescencia su familia pasó una temporada en Europa, más precisamente en Francia y, más precisamente, en París. Alejados de la ciudad por una afección cardíaca de su padre, el joven Manuel emprendía con su familia frecuentes excursiones en bicicleta. En uno de estos paseos llegaron, por azar, hasta el mejor hotel de Versalles. Recuerda: "Cuando llegamos con nuestras bicicletas (me acuerdo de que estaban los espléndidos Rolls Royce de los ingleses), hubo cierta sorpresa. A nosotros no nos importaba nada, estábamos llenos de personalidad" (Vázquez 27). Luego añade que "además" tenían dinero, porque eran argentinos; pero lo que primero los distingue en ese ambiente de riqueza, lujo y ostentosos signos de prestigio, visibles y fácilmente decodificables, no es otra cosa que su personalidad.

2 Este episodio de la autobiografía oral -surcada, por otra parte, de referencias tanto a personalidades de la historia nacional como a hitos culturales europeos- ${ }^{1}$ declara una manera de entender el mundo y, sobre todo, de estar en él. El orgullo y la altivez, así como rastros de fidelidad (o al menos reconocimiento) de las posiciones en el sistema 
jerárquico, aparecen en esta anécdota y nos muestran a su protagonista en un gesto que podría calificarse de esnob. John Sutherland, en su introducción a The Book of Snobs de William M. Thackeray, ${ }^{2}$ ofrece la siguiente serie de atributos que actualmente se asocian con el esnobismo (y que Thackeray de alguna manera organiza en las entregas seriales de lo que terminaría por ser el libro) : "arrogant pride in position, pretension to yet higher position, stiff hauteur to inferiors, supple abasement to superiors, obtuse fidelity to the vertical placings of the rank system" ("Editor's Introduction" 3). ${ }^{3}$ Escribiendo en una época de cambios sociales notorios, Thackeray ofrece tal vez una de las mejores definiciones en virtud de su agudeza crítica y plasticidad. ${ }^{4}$

3 Aunque las definiciones de esnobismo varíen, ${ }^{5}$ parecen coincidir al menos en un aspecto : el esnobismo se manifiesta a través de un universo cerrado de límites precisos - de lo que a él pertenece, de lo que queda excluido y de los mecanismos para reconocer la diferencia se constituye la mirada esnob-y de la posición al respecto de ellos, tanto propia como ajena. El esnobismo como una posición falsa o pretenciosa (aparentar lo que no se es), una aspiracional (deseo de pertenencia) o una de rechazo (desde una mirada externa condenatoria), no dejan de ser, al mismo tiempo, posturas que reconocen una serie de atributos determinados. Y, a diferencia de otras categorías taxonómicas, el esnobismo es una especie de comodín variable, noción más plástica que prefijada de antemano, porque sigue la forma del gusto, de un gusto determinado por un grupo para un momento específico (ajena a los principios por los que se rigen la nobleza, la etnia, el género o la nacionalidad, no se hereda, no está determinada biológicamente, ni por otras categorías igualmente azarosas). Victoria Ocampo, en su comentario sobre The Duke of Bedford's Book of Snobs, titulado "El snobismo" habla de varios esnobismos (clasificables según la disciplina o área del interés humano donde se desarrolle) y parece alertar a los suyos : "No cometamos una injusticia: las convenciones no son monopolio de la aristocracia. Todas las clases tienen su repertorio de convenciones" (269). No está restringida a una clase ni está definida de una vez y para siempre: se trata más bien de una serie de principios vacíos cuyos parámetros se asignan coyunturalmente. Y tal vez el primer gesto esnob consista en estipular la forma que van a adquirir estas variables y en hacerlo de un modo que sea, a su vez, excluyente no sólo en su formulación sino especialmente en su decodificación. Para ello es necesario fundarlo en la arbitrariedad, único modo de tornarlo imprevisible y aun incomprensible para el "profano". Puede ser la personalidad, puede ser una manera de hablar, ${ }^{6}$ pueden ser muchas cosas pero sólo ciertas cosas y ser capaz no sólo de ostentarlas con naturalidad, sino de reconocerlas sin esfuerzo establecen la diferencia ; una diferencia que es frontera absoluta y posición relativa a un tiempo. Su personalidad, entonces, es la llave que abre la puerta de entrada a este mundo exclusivo.

4 Tal vez haya pocos escritores argentinos del siglo XX que el imaginario cultural asocie casi automáticamente al esnobismo como Manuel Mujica Lainez (así como el candidato decimonónico acaso sea Lucio V. Mansilla). La frivolidad es una noción clave en la recepción de Mujica Lainez, ya que en cierto modo organiza la polarización al respecto de sus libros, tal como propone Alejandra Laera en un prólogo que rescata lecturas olvidadas de su obra al tiempo que reclama nuevas. Así, "la pose entre irónica y altiva" (7) lleva tanto al elogio por el lado del gozo como a la crítica, por la futilidad. Y ambas visiones, celebratoria y censora, se proyectan, a su vez, de manera casi especular, sobre las concepciones de su obra : las que valoran su belleza y las que condenan su superficialidad. ${ }^{7}$ El alcance de la pose permea sus lecturas y se alimenta de ellas de un modo que, al decir de Laera, "una lectura actual debería poder desmontar" (7). Pero ¿qué podría obtenerse 
con semejante desmontaje ? O, dicho de otra manera, ¿qué es lo que estas lecturas opacan, obturan o directamente ignoran? Condenar al autor a narrar su clase tuvo, cabe aclarar, sus ventajas : la ilusión de que sus obras permitían que el lector se transformara en voyeur de un mundo de otro modo inaccesible para él. Eso alimentó el éxito de ventas y, paradójicamente, su popularidad. Sin embargo, la mirada "tilinga" alcanza muy rápidamente sus límites : por un lado, reduce al autor al rol de informante nativo, incapaz de ser crítico con lo que se ve conminado a transmitir ; por otro, excluye todo aquello que su pluma deforma, añade o inventa. Lo que se pierde al pensar la obra de Mujica Lainez como una especie de fatalidad de clase es, precisamente, el trabajo literario y, al mismo tiempo, la invisibilización de lo que ese trabajo produce, más allá de lo que cabe esperar de la mera pose.

¿Qué pasaría si entrásemos en la obra de Mujica Lainez por la puerta de servicio ? La novela La casa, publicada en 1954, resulta ejemplar para subsanar estas omisiones. Este relato se vale de la prosopopeya para que la misma casa narre su propia historia que es la de sus habitantes, personas y cosas. Contada desde un presente de decadencia y al borde del derrumbe, relata el principio del fin: una clase que se agota en sus extravagancias y que es testigo, aunque inadvertido, de la expansión o deformación del lugar de otra clase, el personal de servicio y sus zonas sociales aledañas. Dos sirvientas aparecen temprano en el relato y terminan apropiándose de la casa. ${ }^{8} \mathrm{Y}$, por afinidad de los personajes y de su protagonismo en la superficie de la narración, el cuento "El retrato amarillo" ilumina una zona de esta narrativa no siempre visible para la crítica. ${ }^{9}$ Es hora de volver la mirada sobre estos márgenes aparentes para dar al esnobismo de Mujica Lainez la complejidad que supo tener en su momento : no sólo no impidió que forjara personajes ajenos a "los suyos", sino que los dotó de una agencia narrativa decisiva para la construcción de estos relatos.

6 Los sirvientes son, tradicionalmente, un atributo de clase: signo de una posición económica que permite ocuparlos, son también reflejos de sus amos, al decir de Thackeray, pero al mismo tiempo, en la narración, son personajes en sí mismos. Los personajes del servicio son relevantes cuanto menos en estas dos obras prácticamente contemporáneas de Mujica Lainez que exhiben sirvientes enmarcados en casas cuya decadente aristocracia parece perder capacidad de protagonismo al ritmo de la narración. Ensayo aquí una lectura de estos personajes, usualmente omitidos en las lecturas críticas o, cuando incorporados, tomados siempre desde un punto de vista que los somete a la subalternidad y evita considerarlos en sí mismos, alineándose de un modo más o menos visible con una visión narrativa que distribuye los papeles en la ficción de un modo análogo a una visión social. El espacio que los sirvientes ocupan en la superficie narrativa de estos relatos es notable : contrario a lo que de ellos se espera, son visibles, audibles $y$, por momentos, temibles.

\section{Sirvientes, funciones y cuerpos}

7 Los de los sirvientes son cuerpos bajos. Cuerpos que se ocupan de los desechos que producen otros cuerpos, cuerpos altos. La suciedad que producen los cuerpos y sus actividades ocupa lugar, se ve, se huele: debe desaparecer de la superficie de lo perceptible y algo o alguien debe ocuparse de esa operación de la manera más inadvertida posible. La limpieza es, entonces, el efecto de un trabajo que se propone ocultar y cuya visibilidad es huella de ese ocultamiento. En este primer sentido, el cuerpo del sirviente es 
delator : la necesidad de su trabajo denuncia los desperdicios y la imperfección de los cuerpos que los producen. Pero, por otra parte, el sirviente es más que la labor que lo convoca: es un cuerpo que ocupa un lugar y trae, aparejada, toda una serie de actividades, actitudes y comportamientos que le son inalienables. Ante el dilema -todo o nada-, el cuerpo alto no reniega del servicio del que es incapaz de prescindir, sino busca reducir la presencia de aquello que el sirviente trae sin que se lo requiera, aquello que supone una invasión, una amenaza, un exceso inquietante. Cuerpos altos que reniegan de su propia carnalidad no sólo por el rechazo de las propias excrecencias, sino también en virtud de cierta supremacía del pensamiento y del espíritu. Así, las economías del cuerpo y del saber parecen reñidas de modo irreconciliable o al menos los cuerpos altos aspiran a que así sea : preservar para sí mismos una esfera y expeler al otro a las demás. No sólo relegarlo sino demandar que el otro se ocupe de reinstaurar el equilibrio en un ámbito que prefiere no pisar. Los amos tomarán medidas imaginarias para lidiar con esos excesos a la manera en que las narraciones disponen de los sirvientes ficcionales : a veces para dar cuenta de ciertos dispositivos de control discursivo, otras para demostrar cómo se los trasciende o desafía ; algunas más para exhibir sus límites.

En el cuento "El retrato amarillo" de Mujica Lainez y en su novela La casa, los empleados domésticos no sirven: los cocineros no cocinan, los cocheros no conducen, las sirvientas no limpian. El foco se detiene en lo demás, en lo que no debería estar allí y cuya presencia es más productiva para la ficción en tanto elemento perturbador cuanto excesivo. Los contornos de los sirvientes, en especial en el cuento, son más claros y están mejor definidos que los de los amos; en la novela, sus figuras ancilares parecen recortarse, van ganando en definición y agencia en el friso de personajes.

"El retrato amarillo" se centra en el personaje de Miguel, un niño torturado por sus propios pensamientos, que busca saber cosas de su padre, muerto cuando él tenía cuatro años. Miguel recibe un retrato borroso -el que da título al cuento- donde su padre aparece junto a otro hombre, un amigo con quien -le dicen- se encerraba en la biblioteca a leer en inglés, lengua que la madre ignora. El niño vive en una casa apartada de la ciudad con su madre, una especie de presencia fantasmal, y una pequeña legión de sirvientes : Irene, la mucama ; Cándida, "la inmemorial cocinera de la madre de Miguel" (14); el hijo de ésta, Don Fermín, cochero; y "el Absalón", hijo de Don Fermín. Un miembro del servicio vecino se confunde en este grupo : Maximina, hija del quintero de la casa vecina. El abuelo de Miguel y dos amigos del niño completan el repertorio de personajes del cuento : figuras intermitentes y funcionales, el abuelo evoca una gloria en decadencia, francófilo acérrimo y afectado; los amigos, de clases sociales distintas, encarnan formas de amistades homosociales que emulan la que define a su padre para el niño.

En las primeras páginas del cuento, Miguel se acerca a la caballeriza y leemos :

El gemido renació y fue repitiéndose, cobrando tono, como una breve canción angustiada. Miguel dio un paso y distinguió, a la izquierda, sobre el pasto, unas formas blancas, entrelazadas, desnudas. Tardó unos segundos en darse cuenta que los yacentes eran Maximina y el Absalón, el hijo de Don Fermín, pero no comprendió qué hacían, y fue apoderándose de él un terror de esos que lo sobrecogían y lo dejaban helado, tieso.

El pelo rubio de la muchacha se desparramaba sobre el apisonado suelo, como un alga que ondulara en el acuario. El Absalón la mantenía sujeta y la mordía, la besaba. Sus desnudeces relampagueaban en la gran sombra trémula, como si no fueran un hombre y una mujer, sino un ser fabuloso, de nácar fulgente, con 
tentáculos que sin cesar se retorcían. Miguel, temblando, buscó apoyo y empujó un rastrillo. El Absalón alzó la cabeza hirsuta. Su mirada se cruzó con la de Miguel y dio un respingo, pero en seguida la sonrisa ancha volvió a sus labios. Maximina se incorporó también y se tapó los pechos con el pasto. Brilló la arista de sus caderas apenas núbiles.

- ¿Qué querés aquí, sonso ? - dijo la muchacha-. ¡Andáte de una vez !(15)

11 Miguel no entiende sino lo que ve : formas, desnudeces y luz (cosas nacaradas que fulgen, caderas que brillan, pieles que relampaguean). Su reacción como espectador -terror, sobrecogimiento, temblor - no es aprehensible para la razón y el exceso conduce a la mitología, a relatos extraordinarios sobre seres descomunales. ${ }^{10}$

12 Esta escena se fija en la memoria del niño y retorna en la narración, algunas veces puntuado en el relato por el balido de la cabra que siguió a la contemplación perturbadora como un leitmotiv. Así será un "cangrejo de nácar" (17), un “animal fabuloso, el bicéfalo, el que lo perseguía desde que lo descubrió en la caballeriza, con sus ocho tentáculos" (28); y, más adelante, “ese [dragón] de ocho patas que en ningún cuento figura" (33). El exceso inenarrable, que en ningún cuento figura, es la escena de sexo visible de esos cuerpos incomprensibles: el mundo adulto, ocupado en ocultar lo que el niño llamará en adelante "las cosas", siempre entre comillas, se vuelve inteligible a sus sentidos al encarnarse en los sirvientes, cuerpos lo bastante bajos para acercarse a él, para despojarse del pudor, para consumar la relación sexual en la caballeriza.

13 La narración pone al niño frente a estos cuerpos y pone estos cuerpos ante los ojos del lector: cuerpos sexuados que están donde no tienen que estar haciendo aquello que no debieran. Y esas transgresiones, que un lector adulto descifra, no son tan fáciles de desentrañar para Miguel en la siguiente escena que contempla : "Maximina hizo entonces algo raro, incomprensible. Atisbó a derecha e izquierda, y luego entreabrió el escote de su bata hasta la cintura. Miguel no supo si lo que brillaba debajo era su desnudez, pero vio a la cabra hundir la cabeza en ese regazo descubierto" (31). Y a esa escena sigue la descripción de la perplejidad más absoluta : "El miedo que en la casa atendía, el miedo de nada y de todo, fue pasajeramente vencido por un sentimiento misterioso, desatado por eso incomprensible y raro, esa actitud que desordenaba las ideas del pequeño y las arrojaba a rodar, golpeándose, por senderos oscuros" (31). Lo que los sirvientes hacen con esos cuerpos excesivos no sólo alimenta sentimientos irracionales, como el miedo, sino que atenta contra el orden de las ideas - atenta contra la razón.

14 Parte de una clase social subalterna, los personajes de los sirvientes están mejor y más nítidamente definidos que los personajes de los amos. Menos elusivos, no pertenecen al orden de la especulación vaporosa - como el padre-, al misterio de la ausencia y el secreto - como su madre-, ni al decadente espectro que vive en un pasado perdido como su abuelo- sino al presente del cuerpo y sus acciones. La narración, por su parte, otorga una especie de preeminencia sentimental a la incomprensible emoción que sobreviene a Miguel y cierto protagonismo visual a los cuerpos del servicio, metonimias de un deseo posible (a diferencia de los deseos secretos que se intuyen alrededor de sus antepasados). ${ }^{11} \mathrm{El}$ abuelo afrancesado y el padre anglófilo pertenecen a una raza en extinción : sus celebrados refinamientos pertenecen al conjunto de atributos estériles o hipertróficos que desaparecerán en este relato de fin de race. ${ }^{12}$ Sobreviven, en la narración, los cuerpos bajos, desnudos de pretensiones, en apariencia munidos de una lógica ajena y, por ello, no siempre comprensibles.

$* * *$ 
La casa cuenta con una serie de presencias, cuyos estatutos determinan la capacidad o posibilidad de actuar y de hablar (y de que estas manifestaciones tengan consecuencias o carezcan de ellas). Así, los amos y los sirvientes son personas reales que cohabitan en la casa con los fantasmas, por un lado, y con las presencias pictóricas de los habitantes del techo pintado, el tapiz de Beauvais y ocasionalmente las estatuas. Los fantasmas y los seres pictóricos ven más que las personas, pero sus participaciones están restringidas a la percepción de los suyos. La voz de la casa es la de mayor autoridad en el relato : es ella quien narra los hechos e invita otras voces a través de la suya, y es al mismo tiempo quien impone sus juicios sobre todos los seres que la habitan o transitan por ella.

Las jerarquías sociales unívocas de patrones y criados se desdibujan entonces sólo parcialmente por esta proliferación de personajes y voces, las cuales a su vez exhiben sus propios órdenes : ${ }^{13}$

Recuerdo que los del tapiz de Beauvais se pusieron a hacer bromas, pero ellos eran dentro de mi mundo los frívolos -así como los del techo italiano eran los doctos-, de modo que no les presté atención. Presumo que esa frivolidad y esa arrogancia derivaban de que se creían muy superiores a las figuras del techo porque el cartón del tapiz había sido pintado por Boucher, un gran artista, en tanto que el Signor Perelli, según dicen, nunca descolló extraordinariamente. (67)

17 La casa reorganiza sus categorías, ostentando una vez más su esnobismo: el origen europeo del tapiz y la pintura del techo tiene una afinidad con los amos aristocráticos que las figuras del servicio jamás podrán tener. ${ }^{14} \mathrm{La}$ casa describe excesos extravagantes y proliferaciones inútiles (de objetos, de libros, de papeles, de comida) pero eso no consigue empañar la imagen alta que tienen para ella los dueños de casa : el senador y su esposa Clara; sus cuatro hijos, el primogénito Paco -coleccionista y asesino de su hermano, termina recluido por loco-Gustavo, cuya esposa, María Luisa, lo abandona y huye a Europa cuando intuye la decadencia familiar ; Benjamín, último heredero consanguíneo de la casa ; Tristán, el menor de los cuatro, asesinado en su adolescencia, una noche de carnaval (y por ello tempranamente convertido en fantasma) ; y Francis, hijo de Gustavo y María Luisa, único miembro de su generación. Durante los primeros capítulos de la novela, el servicio se reduce a las funciones que de ellos se esperan (aparece un chef a propósito de sus comidas) o como un grupo indiscernible de espectadores de segunda clase, parapetados en algún escondite, tal como el día del carnaval : "detrás de las rejas del escritorio se apretaban las mucamas, los mucamos de librea, el negro Simón, la gente que nunca aparecía por allí, que vivía en las azoteas o subterráneamente, pero a quien el senador había autorizado a mirar la fiesta" (15-16). Pero los movimientos dentro de la casa cambian cuando dos personajes nítidamente definidos se destacan del grupo indiscernible de la gente que nunca aparecía por allí, sin dejar de pertenecer a él : las criadas Rosa y Zulema aparecen en el primer quinto de la novela y llegan para quedarse.

Distintas entre sí pero de algún modo complementarias, llegan a la casa dos sirvientas, Rosa y Zulema. Son hermanas, hijas de distintos padres, y sus descripciones iniciales dan el tono no sólo de los personajes en sí sino sobre todo de la mirada de la casa sobre ellas :

Zulema sabía imponerse, sabía fascinar, y Clara no pudo resistirle. A pesar de la diferencia larguísima de edades, Clara y Rosa poseían caracteres comunes : ambas eran primitivamente sensuales : la Gula gobernaba a la una y la Lujuria y la Pereza a la otra ; y Zulema, que desde niña había subyugado a su hermana mayor con la fuerza de su personalidad, había reunido la experiencia necesaria para vencer los obstáculos que pudiera levantar ante ella alguien similarmente vulnerable. (64, mi énfasis) 
Codiciosas y arteras, pero sobre todo envueltas de un modo casi esencial por pecados capitales, se las presenta ligadas a la sensualidad, una sensualidad primitiva. Esta diferencia trasciende la mera función que las ocupa - sirvientas- para distinguirlas de los amos en un estadio anterior, primordial : va a ser precisamente el deseo desmedido de los amos -en particular, la gula y la lujuria- lo que permitirá que el poder de Rosa y Zulema crezca desmedidamente. Clara, la dueña de casa, extravagante y golosa, será seducida con platos exquisitos traídos a escondidas por la escalera de servicio; Benjamín, el último heredero de la casa, compartirá el lecho amoroso con Rosa, casi a pesar de ella, durante doce años. De este modo, ofreciendo una satisfacción censurable a los deseos secretos y prohibidos de sus amos, Zulema y Rosa van apoderándose poco a poco de la casa.

Los amores de Rosa, sin embargo, habían comenzado años antes, con el cocinero ; en su momento, la casa y sus habitantes celebraron esta relación porque los sacaba del tedio y generaba una vitalidad de la que los amos carecían. La relación con Benjamín, el heredero, es más compleja y menos alegre a los ojos de la casa : la narración coquetea con la idea del matrimonio con una mujer a la que llama inferior; los celos y el ansia de posesión del heredero lo rebajan por debajo de la mucama; los doce años que dura la relación acaban con la muerte de Benjamín, con el testamento en la mano, en que la designa heredera de la casa.

Un tercer amor de Rosa será Leandro, otro joven de clase baja, una especie de timador de medio pelo, interesado en los bienes que las hermanas, tarde o temprano, recibirán ; esta última relación, simultánea con la de Benjamín (y que además coexiste con las relaciones sexuales de Leandro con Zulema), son contadas por la casa con asco. Rosa es una sirvienta cuya sensualidad inicial recorre un arco que va desde la vitalidad necesaria hasta la proliferación abyecta.

22 Cuando Rosa la hereda, la casa se despacha acerca de las sirvientas con una voz que enuncia mandatos de clase traicionados y que, en última instancia, admite esta tragedia como un signo de los tiempos:

Pasé a poder de Rosa [...] en 1934. [...] Sin embargo, nunca la consideré mi dueña, nunca me resigné a incorporarla a las listas reales, las listas de los que rigieron $\mathrm{mi}$ destino legalmente y desde aquí gobernaron. [...] Benjamín me pareció un intruso, pero tenía derecho... mientras que ella... Acaso más tarde la conceptué como la fundadora de una dinastía espuria, encaramada a mi trono temblequeante por azar, a consecuencia de la incertidumbre propia de los tiempos nuevos. (200)

La casa se niega no ya a reconocer sino a aceptar, a convalidar o legitimar, el hecho de que la dueña de casa es la sirvienta. Rosa es heredera legal, porque recibe la casa por medio de un testamento y no llega ahí por azar, sino tras doce años de relación amorosa con Benjamín, a quien en el último mes de vida cuidó "solícitamente" en su agonía.

Una vez propietarias, una de las cosas que más molesta a la casa, es que Zulema reniegue de las labores que la definían como lo que había sido (y que nunca dejaría de ser a los ojos de la narradora) : le molesta su desprecio de las tareas de la sirvienta. Al cambiar su relación con la casa, cambian también las labores que está dispuesta a hacer. Le molestará la mugre a la casa, pero antes le incomoda que se la vea como otra cosa que no sea una mucama :

Yo creo que Zulema eliminó de cuajo las tentativas de limpieza, porque pensó que al ejercer esa actividad reproduciría, cuando se consideraba ya mi señora, la imagen de lo que antes había sido. ¿Fregar, frotar, airear, sacudir, andar con trapos y escobillones? Eso era tarea de mucamos (236) 

casa, ninguna movilidad social podría jamás dar acceso- ni siquiera siendo, como lo es, su dueña. La definición del universo cerrado, cifrado en mármoles y bronces, excluye de sus límites todo lo que la casa pone, en su discurso recalcitrante, fuera del alcance de quien había llegado a la casa como mucama (y de cuyo estigma no podrá deshacerse) :

[Zulema] se vengó de mí y de lo que simbolizaban mis mármoles, mis bronces, mis estucos, mis finos dorados (de todo lo que yo tuve definitivamente de inaccesible para ella, de todo lo que en mí, aun siendo suyo, le escapó, como si detrás de la pompa de cada uno de mis objetos hermosos se escondiera una esencia patricia que los emparentaba y se hurtaba al apasionado celo de su dominio), se vengó con el abandono, entregándome a lo que más podía humillarme, a la infamia de la inmundicia. (236)

A ojos de Zulema, la labor doméstica funciona como metonimia de clase ; por otra parte, a los ojos de la casa, el elemento metonímico sería la mugre. La casa despliega el control discursivo que le brinda la prosopopeya para sancionar y condenar el triunfo de la servidumbre, esa dinastía espuria, sobre la esencia patricia. Los objetos hermosos son menos hermosos y el desprecio que se tiene por el servicio no puede ser detentado por una ex mucama (estigma que jamás dejará de perseguirla). Al reservarse para sí ese lugar, la casa exhibe la tenacidad de su esnobismo : mantiene -a pesar de la realidad - una jerarquía impostada y has-been, obsoleta, abolida por la historia y por los hechos.

\section{Sirvientes, espurios protagonistas}

El efecto de la limpieza viene con un cuerpo que la produce : el cuerpo alto debe trabajar para dar sentido a ese exceso, para construir una diferencia con ese cuerpo bajo, para reducir el impacto espacial de esa presencia. A la hora de narrar ese cuerpo aparece el límite de lo comprensible, en términos de saber pero también del cuerpo. Excesivo e ilegible -o ilegible por excesivo- cuando no sirve, acrecienta el universo expresivo que lleva a la desmesura o al límite de lo cognoscible.

Los cuerpos ancilares desnudos de "El retrato amarillo" se transforman en una de esas "mitologías más torturantes, más complejas que las que encierra la 'Ilíada"' (17b), una sexualidad cuya forma sublime y abismal persigue al narrador como una forma de lo visible, la reproductibilidad que se opone a la esterilidad de su propia estirpe. Lo único que sobreviviría al fin de race sería aquello que no pertenece a él sino que de él depende o dependía hasta ese momento. Lo que vemos en un primer plano del relato es lo que socialmente debería estar oculto y lo que debería verse está ausente, es un secreto, no es accesible a los sentidos. La voluptuosidad de la descripción del cangrejo blanco agrieta la narración nebulosa y sublimada con una carne ajena pero cercana, precisa pero indescifrable. La casa, por su parte, se reserva la última palabra para sancionar, mediante la violencia del control discursivo, el éxito, aunque parcial, de las sirvientas advenedizas. El cuerpo de la sirvienta, así como sus malas artes, es un problema, así como lo es la clase, y la relación con las instalaciones y la belleza. Más aún : lo que en las sirvientas encuentra la casa de imperdonable es la negación de un estatus al que podrían anhelar. Propietarias de la casa, no imitan a las personas para quienes trabajaban (y con quien entablaban relaciones más complejas), sino que reniegan de todo : de lo que eran y de lo que podrían ser. Llevan a la casa a la mugre, primero negándose a limpiarla, y luego a la destrucción, quemando las genealogías y dejando que la casa se derrumbe. 
Estos excesos a disciplinar, en la narración, resisten : rumores y explicaciones ocultas, como formas del conocimiento; enfermedades, sexualidad, reproducción, como formas anómalas del cuerpo. Estos sirvientes literarios activan la puesta en narración de dos economías : una economía del cuerpo y una economía del saber, así como el encuentro entre ambas, por medio de disrupciones excesivas. Las formas del exceso no siempre se encauzan y por momentos, precisamente por eso, la narración no consigue someterlas a la autoridad de su control.

\section{La casa, la nación}

El esnobismo, ya se sabe, no es categoría tan desdeñable como alguien supusiera, sino avanzada

ingenua de la cultura, muchas veces, audacia ignorante en el mundo de las ideas, curiosidad saludable, pasión malsana por la novedad. En una sociedad tan quietista como la nuestra, el esnobismo es doblemente beneficioso y heroico.

Francisco Umbral Diario de un snob, 10

La lectura alegórica de la novela no es tan sencilla como podría parecer a primera vista ${ }^{15}$ aunque, pensando en el contexto de su publicación, tal vez sea inevitable. La casa se publicó en 1954 : dos años después de la muerte de Eva Perón (hecho a partir del cual se acentuó la persecución de declarados antiperonistas) y un año después del encarcelamiento de Victoria Ocampo ${ }^{16}$ (y casi ocho desde el resonado ascenso de Borges a inspector de "aves y conejos", Autobiografía 112). Sin embargo, una lectura política en la que resuenen los panoramas nacional e internacional no necesariamente conduce a la iteración de modelos conocidos de interpretación inequívoca. ${ }^{17}$ La solución al problema político es, para Mujica Lainez, estética (no por eso menos política). ${ }^{18}$ Aunque la voz narrativa esté alineada con una idealización de sus dueños primigenios, las dos clases sociales principales - patrones y servicio- no están solas : los fantasmas y los personajes del tapiz y el techo tienen voz y realidad. Contraria a la miopía que suele atribuirse a la concepción social y política del autor, esta novela exhibe un interés que va más allá de "los suyos" : "Mujica Lainez se caracteriza por combinar la pertenencia a la élite cultural de los años de 1950 con una preocupación por delinear el nuevo mapa de clases de la sociedad contemporánea que, aun con diferencias irreductibles, parece propia de ese momento" (Laera 12). Las jerarquías y distribución de prestigios (y de autoridades) es una compleja red de tensiones en constante movimiento, donde ninguno de los grupos está exento de imposibilidades, carencias e incluso crímenes. En definitiva, el deterioro en apariencia irremediable de la casa llega de mano de las sirvientas -últimas propietarias legítimas, mal que le pese al edificio-, pero eso se debe a un agotamiento tan innegable como irreversible de una aristocracia exangüe.

$\mathrm{Si}$, como parece a primera vista, esta novela acusa a las sirvientas de incapacidad de conducción tras el uso avezado de sus malas artes, la acusación también -y aun más incisivamente- apunta a la clase alta que la ocupó otrora : su esterilidad (por vaporosa, por insustancial, por nostálgica, por improductiva) la lleva a refugiarse en otra para no ahogarse en su propia vacuidad (acentuada por el horror vacui de la superocupación material de los espacios y detalles siempre inútiles, siempre redundantes). ${ }^{19}$ Llevándolo a 
los hechos concretos y desnudos de apreciaciones subjetivas (de las que abundan en el relato), la casa termina en manos de las sirvientas por dos motivos : por un lado, porque no quedan herederos de sangre que puedan recibirla (el único sobreviviente está encerrado por loco y, secretamente, por asesino) ; por otro, porque Benjamín, el último propietario consanguíneo, se la dejó a Rosa en su testamento. Aunque sobre todo la casa se resista a aceptarlo, la narración hace de Rosa una propietaria legal (por el testamento) y, en la lógica narrativa, legítima (por compartir con Benjamín más de una década de relación protomatrimonial).

Cuando la novela se publica, Sur le dedica una reseña, donde Eduardo González Lanuza afirma: "Mujica Lainez se lanza denodadamente 'en busca del tiempo perdido', de un tiempo sólo recuperable en la añoranza. ${ }^{20}$ Un tiempo perdido, no tanto por él personalmente como por los suyos" (34). Y, más adelante, asegura: "Sólo un hombre perteneciente a la clase que experimentó esas solicitaciones puede intuir el orden secreto que presidió el evidente desorden de tales aglomeraciones lujosas" (35). Así, el autor funciona estrictamente como un vocero de clase, ofreciendo la visión que sólo un insider podría tener, pero además sabe cosas (o las intuye) que son, como no podría ser de otro modo, secretas. Pero por el contrario, la lectura de González Lanuza establece también lo que el autor no puede hacer (aunque, de hecho, lo haga) : "El autor, por descontado, no enjuicia a una clase que siente como suya. Eso estaría tan fuera de lugar como si los emigrados del 'ancien régime' hubieran participado en los tribunales populares que llevaban a la guillotina a sus parientes" (36).

El punto de vista de la casa es poderoso : González Lanuza lo acepta - un punto de vista que la novela presenta desde el fracaso- hasta el punto de adoptarlo como propio, al negar a Zulema y a Rosa, a quienes no vacila en tildar de "intrusas", la genuina posesión del edificio: "la casa nunca llega a ser auténticamente suya" (37). Pero tras ese gesto crítico de aparente docilidad hay una resistencia voluntaria (y voluntariosa) a la novela misma, un esmero que niega parcialmente el relato. $Y$ para eso necesita falsear el lugar que estos personajes tienen en las páginas: "Claro está que cuando en la parte final intervienen personajes de otra clase, casi podría decirse de otra casta, el autor no puede prescindir de su enfoque" (37, énfasis añadido). Zulema y Rosa aparecen en la página 63 (en la primera edición de 295 páginas) y lo hacen en un momento en que las posibilidades narrativas de la familia de los patrones ya han dado todo de sí, cuando el relato familiar ya ha agotado sus posibilidades. La vitalidad no sólo sexual sino narrativa del relato depende, a partir de entonces, de ellas.

Pero la miopía crítica no responde exclusivamente a esta publicación ; en Contorno correrá parecida suerte al año siguiente. Por un lado, Antonio Pagés Larraya "incluye un extenso y favorable comentario sobre [...] su tematización de la decadencia de la élite" (Laera 12); que la élite es visible -con un signo o su contrario- es innegable; no lo es tanto el servicio doméstico. Y si bien vale la pena rescatar ese comentario (en un texto que en realidad versa sobre Julián Martel), en el mismo número de la revista aparece un artículo entero dedicado a La casa, firmado por Rodolfo Mario Pandolfi : en él se censura la novela por la inmutabilidad que transmite (37a), su ahistoricidad (37b) y su escapismo. Reconoce el contenido alegórico de la quema de los cuadros genealógicos (36-37) pero hasta allí llega la lectura de interpretación. El autor parece más empeñado en acusar a Mujica Lainez de "literato de salón" (36a) que en leer aquello que, tal vez a pesar de sí mismo, este literato de salón haya terminado por escribir. De este modo, Pandolfi, en su reseña engañosamente titulada "Mujica Láinez [sic] y el gran cambio", incurrirá en el mismo 
gesto crítico que González Lanuza al abocarse a mirar (en sentido contrario que su colega) el "desmoronamiento de los clanes aristocráticos" (36a) y reducir la importancia de las sirvientas en una narración que las exhibe, sin remilgos, como auténticas protagonistas. ${ }^{21}$

Nada inocente hay en dos sirvientas arteras, sexual y sensualmente hábiles, que se aprovechan del lado oscuro de una aristocracia en decadencia ; lejos de eso, La casa traza un panorama horrible, tal vez como el autor lo percibía en ese momento. Nada de maniqueísmos: la aristocracia está dotada de caracterizaciones de contornos tan aberrantes como los del servicio y los lúmpenes que pululan a su alrededor. A la hora de escribir la novela, la alarma histórica de Mujica Lainez no se conforma con el antiperonismo de su entorno para trazar una analogía directa, ${ }^{22}$ pero tiene en cuenta constantemente -ya desde el principio de la composición hasta décadas más tarde, desde el punto de vista de la recepción-, el vínculo patente de la casa con el país. Entre las notas de composición se lee: "Luego, ese mundo bajo se apodera de la casa. La casa se humilla. Es un poco lo que ha sucedido con nuestro país" (191, de las Notas para la escritura de la novela, citadas en Villordo). En una entrevista publicada casi treinta años más tarde, señala: "Pero mucho más importante que Los ídolos es La casa, uno de mis libros más logrados por lo que tiene de imaginativo y de poético y, al mismo tiempo, porque está muy adherido a la historia de nuestro país" (75). Entre casa y país, el relato. Es "un poco lo que sucedió con el país", está adherido a su historia, pero sigue siendo ejemplar y destacable, precisamente y ante todo, por lo que tiene de imaginativo y de poético. La confusión entre el esteticismo de su pose y la supuesta falta de preocupación política de su obra se debe, en parte, a cierta pereza crítica. ${ }^{23} \mathrm{El}$ credo político de un escritor esnob no deja de ser, por principio, estéticamente comprometido.

\section{Coda. "Trabajar : destruir"}

Tal vez la escena de interpretación política más transparente no sea un episodio central en la novela sino de uno más bien marginal que, en lugar de incumbir a las sirvientas, dispone ante los lectores a dos albañiles. Durante la demolición de la casa, se suceden varios días de lluvia, en los cuales las obras se interrumpen. El capítulo tres comienza así :

Hace tres días que llueve. Los obreros me han dejado tranquila : llueve tanto que les es imposible trabajar. Trabajar: destruir. Ayer, a las once de la mañana, no había dentro de mí más que dos hombres. Asaron unos trozos de carne al reparo de lo que queda del gran comedor y se pusieron a devorar y a pegarle unos besos amorosos a la botella de vino. Encendieron el fuego con astillas de la vieja boiserie -la parte que estaba junto a la chimenea, la parte que se rajó al quitarla-, y con unos fragmentos del techo italiano irreconocibles. Uno de ellos descubrió un pedazo del óleo del Signor Perelli, retorcido, resquebrajado, sucio ; le echó encima un vaso de soda y se puso a frotarlo. Debajo aparecieron la sonrisa cortesana de la dama del quitasol, sus verdes ojos, sus perlas barrocas...

- ¿Sabés que está lindo ? - dijo dirigiéndose a su compañero-. Me lo voy a llevar para casa ; lo limpio, le pongo un marquito y se lo regalo a la patrona.

-Dejá esa porquería - contestó el más viejo, y se engolfaron en una conversación sobre la guerra de Corea. (58)

La impronta antiperonista apunta a los obreros, columna vertebral del movimiento, y, con ellos, a cierta retórica del trabajo. En una reversión de la oposición entre alpargatas y libros $^{24}$, los albañiles aparecen frente al óleo: la barbarie proletaria arrasa con lo que queda de la casa sin capacidad alguna para discernir los restos de la belleza en sus despojos. Para equiparar trabajo y destrucción, el relato no necesita recurrir más que a un 
signo de puntuación ; sin siquiera conjugarlos, limita la mediación a los dos puntos que funcionan como un signo igual. No los compara ni se detiene en arduas equivalencias; recurre a la potencia de la economía.

La casa, en su sostenido lamento nostálgico, compara las comidas fastuosas que tenían ocasión en el mismo espacio con la que contempla en ese momento, precaria y popular, "con olor a ajo" : "Otras comidas... otro mundo..." (59). La alteridad parece absoluta, de mundos que no se encuentran ni tienen nada en común. Pero ni siquiera aquí, mientras contempla a dos obreros asando carne con el fuego alimentado con su propia boiserie, la casa es tan maniquea. Por el contrario, hace la siguiente salvedad: "pero me reconfortó hasta cierto punto que esos dos obreros comieran ahí y hablaran como siempre de la guerra, de una guerra, de su guerra, mientras afuera caía la lluvia; y escuchar el ruido familiar de los platos, de los cuchillos, gracias a los cuales el comedor seguía siendo eso, el comedor" (59). Son inelegantes, sí, cuando besuquean la botella ; primitivos, porque no entienden de maderas más que para hacer un asado ${ }^{25}$ y no conversan sino que se engolfan en conversaciones; y también son ignorantes, cuando desprecian como porquería un objeto bello, una de las imágenes del techo italiano. Pero, para la casa, autoridad del relato, quien los pinta así, son, mal que le pese, necesarios. Y lo son porque, ausentes todos, amos y sirvientes, despojada la casa de pinturas, parquet y boiserie, son los únicos que quedan $\mathrm{y}$, con su carne asada, quienes dan sentido al comedor en tanto tal. Y para eso, la casa, agonizante, los necesita : para que el comedor siga siendo lo que ella, en su soledad, necesita que sea para seguir siendo ella misma, mientras pueda seguir con el relato.

La diferencia entre ambos obreros es, en cierto modo, la posibilidad de reconocer la belleza, aun en su ignorancia. Y esa consciencia estética es clave para Mujica Lainez y para su concepción del esnobismo. Joaquín Soler Serrano lo entrevistó para A fondo, en la Radiotelevisión Española, en un programa emitido el 19 de junio de 1977. Allí, acaso al pasar, Soler Serrano le pregunta por su esnobismo :

JSS : Por otra parte me cuentan que a pesar de tu fama de hombre aristocrático[...], esnob, más o menos sofisticado...

MML : Todo eso no es cierto.

JSS : ...no tienes ningún asco a andar en los autobuses, en los metros...

MML: Ah, no, no, no... No, no, qué... En los autobuses, en los metros y en esa cosa atroz que hay en mi país que se llaman "los colectivos" [gesto], donde andas prensado, así. (Soler Serrano 0.00s-0.37s)

Mujica Lainez reniega de su "fama", de su esnobismo, precisamente ejercitándolo, tachando de atroces los autobuses locales, con un gesto de repugnancia intraducible. La espontaneidad de su pose, que niega su condición, termina por ser aquello que la confirma. Lo que lo diferencia del resto de pasajeros es la atrocidad, es decir, el entrecomillado ; sin embargo, aunque no lo necesite, él puede tomar "esa cosa atroz" que hay en su país, cómo no, sin perder ninguno de los adjetivos que Soler Serrano le atribuye, como no los había perdido al llegar en bicicleta al mejor hotel de Versalles. El trabajo estético de Mujica Láinez hace de la personalidad -la de la familia en bicicleta cuando adolescente, la suya propia frente al entrevistador europeo como escritor consagrado y pasajero de atroces colectivos- una apuesta decisiva en sus ficciones. Al dotar de personalidad a las sirvientas, las hace capaces de actuar por y para sí mismas, despojándolas de su condición y haciéndolas, de alguna manera, libres. 


\section{BIBLIOGRAPHY}

Cárdenas, Isabel Laura. Ramona y el robot. El servicio doméstico en barrios prestigiosos de Buenos Aires (1895-1985). Buenos Aire: Ediciones Búsqueda, 1986.

Cruz, Jorge. Genio y figura de Manuel Mujica Lainez. Buenos Aires : Eudeba, 1978.

Dunstan, Inés. “The Lowest Kitchen Maid : Evita as an Evil Mucama (1946-2005)”. Hispanófila 173 (2015) : 203-17.

González Lanuza, Eduardo. “La casa”. Sur 231 (1954) : 98-102. Reproducido en número especial. Jitrik, Noé. “Exquisitos y justos”. Página 12. 3 de abril de 2007. <https://www.pagina12.com.ar/ diario/contratapa/13-82698-2007-04-03.html>.

Laera, Alejandra. "Prólogo". Manuel Mujica Lainez. Los dominios de la belleza. Antología de relatos y de crónicas. Buenos Aires : Fondo de Cultura Económica, 2005. 7-36.

Laudanno, Claudia. "Interdiscursividades artístico-literarias en la obra de Manuel Mujica Lainez". El Cuento en Red. Revista Electrónica de Teoría de la Ficción Breve 3 (2001) : 49-59.

Mujica Lainez, Manuel. La casa. Buenos Aires : Editorial Sudamericana, 1954.

---. El gran teatro. Buenos Aires : Sudamericana, 1980.

---. Un novelista en el Museo del Prado. Barcelona : Seix Barral, 1984.

---. "El retrato amarillo". Ficción 3 (1956) : 11-62.

Ocampo, Victoria. "El snobismo. Consejos del duque de Bedford a quienes quieren alternar con la aristocracia". Testimonios. Octava serie (1968-1970). Buenos Aires : Editorial Sur, 1971. 267-76.

---. y Gabriela Mistral. Esta América nuestra. Correspondencia 1926-1956. Buenos Aires : El cuenco de plata, 2007.

Pandolfi, Rodolfo Mario. "Mujica Láinez y el gran cambio”. Contorno 36 (1955) : 36-38.

Puente Guerra, Ángel. “Las mitologías personales de Manuel Mujica Lainez”. Sur 358-359 (1986) : 193-211.

Schmidt, Rachel. "Hacer que los cuadros hablen : la problemática del marco en Un novelista en el Museo del Prado, de Manuel Mujica Lainez". Revista Canadiense de Estudios Hispánicos 28.1 (2003) : $119-35$.

Soler Serrano, Joaquín. "Entrevista a Manuel Mujica Lainez". A Fondo. RTVE. 19 de junio de 1977. < https://www.youtube.com/watch?v =7NM8YkeQ_yA\&t =75s>.

Sutherland, John. “Editor's Introduction” y “Appendix : The Etymology of Snob”. En Thackeray. Thackeray, William Makepeace. The Book of Snobs. Ed. John Sutherland. Nueva York : St. Martin's Press, 1978.

Umbral, Francisco. Diario de un snob. Barcelona : Destino, 1973.

Vázquez, María Esther. El mundo de Manuel Mujica Lainez. Buenos Aires : Editorial de Belgrano, 1983.

Villordo, Oscar Hermes. Manucho. Una vida de Mujica Lainez. Buenos Aires : Planeta, 1991. 
Zangrandi, Marcos. "Monstruos de Mujica Lainez : clase, cuerpo y medida”. Literatura y lingüística

29 (2014) : 95-108.

\section{NOTES}

1. Mujica Lainez se construye retóricamente como escritor a través de una serie de "puntos de partida" : la familia y la sangre, el viaje iniciático y dos instituciones clave, el diario y el museo : "Y bien, antes de empezar a escribir mis verdaderos libros tuve una serie de ventajas básicas que pueden resumirse así. En el origen, todas esas sangres literarias que llevaron a que me contaran esas ricas anécdotas familiares. Luego el viaje a Francia siendo yo muy chico ; las pocas cosas que sé de verdad, las aprendí entonces. La gente que conocí en el diario La Nación me enseñaron mil cosas. Los viajes me enriquecieron notablemente. El Museo de Arte Decorativo me fue utilísimo, sobre todo porque soy un maniático de los objetos, como se puede ver en mis libros. Y estos fueron [...] los puntos de partida para hacer lo que se llama, un poco suntuosamente, una obra" (Vázquez 47).

2. Victoria Ocampo, en un breve texto titulado "El snobismo" hace referencia a Thackeray, quien también aparece varias veces mencionado en otra gran novela que abunda en poses esnobs de Manuel Mujica Lainez, El gran teatro.

3. “Orgullo arrogante de la propia posición, aspiración a una aun más alta, rígido desdén hacia los inferiores, rebajamiento servicial ante los superiores, fidelidad obtusa hacia las ubicaciones verticales del sistema de rangos" (mi traducción).

4. Thackeray escribe sus columnas sobre el esnobismo en plena Revolución Industrial : "Flux is the normal condition of the century, but uncertainty in this decade [1840] seems to have been extreme. The year 1846, in particular, was dominated by two large unsettling events which at first seemed to add to the prevailing crisis, but in fact were to usher the country into an era of stable and long-lived prosperity. The first was the repeal of the protectionist corn laws which climaxed the progress towards universal free trade Peel had inaugurated in 1841 . The second was railway mania" (5). [El estado normal de la época es el cambio constante, pero la incertidumbre de esta década parece haber sido extraordinaria. Dos sucesos inquietantes dominaron el año 1846 en particular, en lo que al principio parecieron agravantes para la crisis que imperaba, pero que en realidad llevaron al país a una era de prosperidad estable y prolongada. El primero fue la revocación de las proteccionistas Leyes del maíz que culminaban el progreso hacia el libre mercado que Peel había inaugurado en 1841. La segunda fue la manía del ferrocarril.]

5. En la definición del Diccionario de la Real Academia Española, se lee : "Persona que imita con afectación las maneras, opiniones, etc., de aquellos a quienes considera distinguidos”. El Oxford Dictionary ofrece la acepción del sustantivo, como "A person with an exaggerated respect for high social position or wealth who seeks to associate with social superiors and looks down on those regarded as socially inferior" [Una persona con un respeto exagerado por la posición social elevada o la riqueza, quien busca relacionarse con personas socialmente superiores a sí y desprecia a las inferiores], y como adjetivo como "A person who believes that their tastes in a particular area are superior to those of other people" [Una persona que cree que sus gustos en un ámbito particular son superiores a los de otra gente]. Según Victoria Ocampo, "En el Pequeño Larousse Ilustrado aparece la palabra snob como sinónimo de vanidoso".

6. En El gran teatro, tal vez la novela donde Mujica Lainez desmonte con más perspicacia momentos de abierto esnobismo, Salvador recibe una lección de su bisabuela, quien corrige su forma de hablar : "Nosotros-pensaba-, nosotros significará los Gonzálvez y los Zúñiga. Y habrá otros más. Los que no decimos al Colón (que es como se debe decir) sino a Colón (que es como nosotros debemos decir). ¿Por qué? ¿Quiénes somos nosotros? Debemos decirlo así para distinguirnos? ¿Es una clave? ¿Hablamos nosotros en clave ?” Y Salvador se prometió, desde ese 
momento, vigilar a quienes mencionaban al Colón (a Colón) : eso lo ayudaría a clasificarlos. Entretanto, lo avergonzó no haber sido iniciado antes en esa particularidad, propia de su clan, de los suyos, de nosotros". (El gran teatro 34). Luego de la lección y la reflexión, el inexperto Salvador se dedica a mirar bajo esta nueva luz a la gente que lo rodea en el teatro.

7. Para Laera, la frivolidad de Mujica Lainez es ambivalente: "Del lado del elogio, la frivolidad se convierte en un goce profundo de la vida, en una capacidad para disfrutar de lo cotidiano y compartirlo en familia y con amigos. Del lado de la crítica, en cambio, la frivolidad se despliega en otro sentido: Mujica Lainez sería fútil, veleidoso, inconstante; su obra, por extensión, insustancial y ligera." (Laera 7)

8. Según Mujica Lainez, esta anécdota es verídica. "Había frente al Jockey Club de la calle Florida una residencia cerrada que siempre me intrigó y que, cuando uno se acercaba, percibía un olor a gato espantoso. Un día, Melián Lafinur me contó que el último dueño, un solterón, se la había dejado a las sirvientas, que, desde entonces, se habían encerrado allí, habían dejado de limpiar y salían sólo una vez por semana para ir al mercado” (Vázquez 76).

9. Según el autor, este cuento inicialmente iba a ser una novela. "Empecé a escribir una novela, que transcurría en el Tigre y que se llamaba El retrato amarillo (hace muchos años), y le di a leer a Anita [de Alvear, su esposa] unas páginas y me dijo : ¿Cómo te metés con ese tema, con esas cosas tan ambiguas ?' Entonces me sacó todas las fuerzas para escribir y abandoné el libro. Mucho después se publicó lo que había escrito, creo que en 1956" (Vázquez 111-12).

10. Marcos Zangrandi, en un análisis de este cuento y otras obras del autor con especial atención a lo monstruoso, se refiere al "cuerpo extraño e inclasificable como objeto de deseo" (96). Zangrandi entiende la "monstruosidad como borde sociocultural" (96).

11. Tema recurrente en la obra de Mujica Lainez, la voluptuosidad de las clases bajas aparecerá de nuevo en un brevísimo déjà vu en El gran teatro. No ya entre sirvientes sino entre la madre de Salvador -joven de familia aristocrática que recuerda su infancia- y un peón de campo, se produce otra escena de voyeurismo infantil: "Vestida de ese modo, el niño de seis años la sorprendió una tarde, en el campo, detrás de una parva. Abrazaba el torso desnudo, bronceado de un joven peón : pegaba contra él su vestido claro, cubierto de flores rojas y amarillas" (180). La voz narrativa la califica a continuación de "imagen atroz".

12. Esto es la degradación última-moral, intelectual y sobre todo física-de una estirpe. De alguna manera, la llamada saga porteña (y, según las lecturas, Bomarzo), tratan este indeseable fin de race, donde no se designan valores positivos. Jorge Cruz afirma que toda la "'saga de la sociedad porteña', como testimonio de un grupo social, registran un proceso de decadencia ; una clase dirigente pierde fuerza, ejemplaridad y poder, en gran parte debido a la corrosión de un germen destructor que lleva dentro" (112).

13. Este procedimiento es frecuente en Mujica Lainez y tiende a relacionarse con su labor como crítico de arte (Laudanno). Tal vez el libro donde más recurra a él sea Un novelista en el Museo del Prado (1984), poblado por cuadros y esculturas que "hablan". Al respecto, ver Schmidt.

14. En este sentido, la literatura de Mujica Lainez persigue esa especie de misión declarada de convertir la tabula rasa que era Buenos Aires poblándola de importaciones : "Lo que quise hacer, cuando escribí Misteriosa Buenos Aires, es darle a esta ciudad mía mitos que la comunicaran con las grandes ciudades del mundo, que la vincularan a las grandes civilizaciones, porque ésta, no nos engañemos, era una aldea perdida en el extremo de América" (Vázquez 64). Y, más adelante, relativiza un poco los resultados, teniendo en cuenta la materia prima con la que debió trabajar : “Te prevengo que Buenos Aires no es Brujas, ni Florencia, ni etcétera, etcétera... Yo he hecho lo que pude con Buenos Aires" (81).

15. La interpretación directa de Rosa y Zulema como encarnaciones de Eva Perón y Benjamín como su esposo (Dunstan 309), por ejemplo, omite los matices que la novela ofrece en abundancia. 
16. En una carta escrita tras ser liberada, que llamó "un "rapport" Ocampo afirma: "Yo no he hecho nada fuera de ser antiperonista y de censurar à haute et inteligible voix la dictadura monstruosa que nos aplasta" (223). Gabriela Mistral tomó parte en las actividades para que fuera liberada escribiendo un telegrama a Perón a fines de mayo de 1953 (Ocampo y Mistral 217).

17. El año en que la casa pasa a manos de las sirvientas, por ejemplo, coincide con la asunción de Hitler en Alemania. La correspondencia directa sería una exageración; ignorar que varios escritores del entorno de Mujica Lainez calificaban de dictador a Perón sería otra.

18. Una versión tal vez extrema por flagrante del contraste entre el problema político y la solución estética es notable cuando habla de sus traducciones de Shakespeare durante el gobierno peronista : "Empecé como coleccionista [de versiones de los sonetos de Shakespeare] y terminé como traductor. Eso sucedió durante aquel gobierno en que no fui feliz. Para olvidarme, cada mañana traducía un soneto y durante horas me olvidaba de lo que estaba sucediendo en el país, Shakespeare me arrebataba" (141).

19. Así, en "El retrato amarillo", el relato de fin de race de la degradación de las virtudes como camino directo al linaje que se pierde contrasta en su visibilidad y carnalidad con lo vaporoso y ausente de la clase en decadencia.

20. Ángel Puente Guerra señala : "Recordemos, no obstante, que la retratada por Mujica Lainez es una sociedad en vías de extinción, y por eso los síntomas de la decadencia, hábilmente dosificados, van acentuándose con el correr de las páginas" (199). El crítico atribuye un ánimo celebratorio al tono de La casa: "una de las coordenadas de la novela contribuye a apuntalar el prestigio de ese mundo que se derrumba" (204).

21. Incluso hasta 1986, en el número póstumo de Sur dedicado a Mujica Lainez, impera la complicidad con la casa y la censura moral que de ella se desprende : "Para la casa, sin embargo, no ha sonado todavía la hora más amarga [con la decadencia económica de la familia] : será durante el infame reinado de las criadas cuando conozca el horror de la degradación que sumará al éxodo de sus obras de arte el abandono de los aposentos, invadidos por hedores vergonzantes" (Puente Guerra 199). Para Jorge Cruz, en 1978, la destrucción de la casa se manifiesta como "el peso de un castigo" (112). También en 1986, Isabel Laura Cárdenas propone La casa como la novela que ejemplifica "El servicio doméstico en la literatura argentina" (70). Según Cárdenas, "[1]a historia se desarrolla entre niñeras y sirvientes, el valet de Paco y el preceptor de Francis, cuya única ocupación consistía en que no lo confundieran con el servicio doméstico" y resume la presencia de Zulema y Rosa así: "Finalmente, cuando el último dueño de la casa se aleja dos mucamas se apoderan de ella" (71).

22. Como ha sabido leerse "Casa tomada", esa casa "espaciosa y antigua" publicada alrededor de diez años antes, en clave de alegoría antiperonista.

23. Laera comenta, en este sentido, la escena más explícita de su narrativa : ¿Cómo entender, en el marco de esta minimización de lo político, la irrupción brutal que hará cuatro años después en una de sus ficciones? Porque en 1976, cuando Mujica Lainez publique Sergio, esa novela de iniciación de un joven hermoso y sensual, introduce la única escena explícitamente política de su narrativa : en el desenlace, Sergio muere, a la salida del aeropuerto de Ezeiza y a causa de una confusión, en manos de un grupo armado que atraviesa a balazos las ventanillas del coche en el que viaja" (18). En La casa, por el contrario, belleza y política no serían polos tan reñidos ni excluyentes.

24. Al respecto de la consigna "alpargatas sí, libros no", Noé Jitrik explica : "Era o parecía una opción : o se estaba con los libros, lo que suponía valores culturales exclusivos y excluyentes, o se estaba con las alpargatas, sustantivo que implicaba justicia social. En su irrupción combativa, sólo de un lado porque nadie replicaba invirtiendo los términos, nadie decía 'alpargatas no, libros sí', la opción fue vista, por ciertos sectores afiliados a los libros, o sea a la cultura, como reaparición de una barbarie". 
25. El folclore oral del antiperonismo incluye la imagen de los beneficiarios de viviendas sociales quemando el parquet de sus nuevas casas, en parte por ignorancia y por apego a sus costumbres, para hacer asados.

\section{ABSTRACTS}

Manuel Mujica Lainez regards snobbism as a matter of personality. Framed by two biographical episodes that delineate his opinions on the matter, this article rereads the short story "El retrato amarillo" ["The Yellow Tale"] (1956) and mainly his novel La casa [The House] (1954), published at the height of the Peronist regime, paying special attention to the servant protagonists, Rosa $y$ Zulema. By highlighting these characters that are usually relegated for their ancillary position, the article resists the critical bias that tends to follow the narrator's point of view-that of the house, which narrates through prosopopoeia-, thus acknowledging the often unseen contradictory forces that move the plot forward. Against critical readings that follow a purported authorial intention, this study ultimately challenges the reading protocols that follow the socially determined tendency to ignore the roles of domestic servants. The article's coda focuses on a minor scene in the novel, in which two masons grill meat in the majestic house in ruins, in order to suggest that the interpretive focus should expand to consider the political reality in which this novel was created.

Para Manuel Mujica Lainez el esnobismo es una cuestión de personalidad. Entre dos escenas biográficas que definen su posición al respecto, este artículo revisa el cuento "El retrato amarillo" (1956) y, sobre todo, su novela La casa (1954), publicada en plena época peronista, y en especial los personajes de las sirvientas que la protagonizan, Rosa y Zulema. Al reivindicar esos personajes habitualmente subsumidos por su condición ancilar, se propone una lectura que se aparta de una obediencia fiel al punto de vista que domina la obra -la casa que habla por el recurso a la prosopopeya- y devuelve al relato las fuerzas en conflicto que mueven la acción. Tras una revisión de lecturas críticas que obedecen a una supuesta intencionalidad autoral, esta interpretación propone, en última instancia, desafiar protocolos de lectura que siguen una orientación convencional de la mirada, socialmente prescripta para ignorar al servicio doméstico. A modo de coda, el artículo se detiene en una escena mínima de la novela, donde dos albañiles hacen un asado entre los restos fastuosos de la casa, para expandir el alcance interpretativo a la luz de la realidad política nacional del momento en que se escribe.

Pour Manuel Mujica Lainez, le snobisme est une question de personnalité. Entre deux scènes biographiques qui définissent sa position à cet égard, le but de cet article est de revisiter la nouvelle "El retrato amarillo" ("Le portrait jaune", 1956) et, surtout, son roman La casa (La maison , 1954), publié en plein essor du péronisme, en accordant une attention particulière aux deux protagonistes, les domestiques Rosa et Zulema. Par la revendication de ces personnages habituellement confinés à leur condition ancillaire, cet article propose une lecture qui s'éloigne de l'obéissance fidèle au point de vue qui domine l'œuvre - la maison qui parle par le biais d'une prosopopée - et qui rend au récit les forces en conflit qui sont les moteurs de l'action. Une fois présentées les lectures critiques obéissant à une supposée intentionnalité auctoriale, cette interprétation entend questionner ces protocoles de lecture qui suivent, justement, une orientation conventionnelle du regard, un regard qui serait socialement prescrit pour ignorer le 
personnel domestique. En guise de coda, l'article analyse une scène minime du roman, où deux maçons font un barbecue entre les restes somptueux de la maison, ce qui permet d'élargir la portée interprétative à la lumière de la réalité politique nationale au moment de l'écriture du roman.

INDEX

Palabras claves: Sirvientes, esnobismo, crítica social, clases, peronismo

Keywords: Servants, snobbism, social criticism, social classes, peronism

Mots-clés: domestiques, snobisme, critique sociale, classe sociale, péronisme

AUTHOR

MARÍA JULIA ROSSI

CUNY, John Jay College 